\title{
Multilingualism in Prizren: Language Use and Language Policy
}

Jasmin Jusufi

Dr.sc.

\section{Abstract}

This research focuses on theoretical and practical issues of multilingualism in Prizren, the Republic of Kosovo's most linguistically diverse city. It examines the city's linguistic landscape, culture, and values, investigating language use at home, in public, and in institutions. It analyzes language legislation and its often uneven implementation. In the last 20 years the language situation in Prizren has changed dramatically. This research attempts to provide a clear picture of the current language situation of Prizren in the new and independent Republic of Kosovo, and is relevant for the general public, minority communities, government, non government and international organizations. The research was conducted in order to shed more light on the concept of multilingual societies. The central sources for this research are the Constitution of the Republic of Kosovo, the policy on language rights and language use in the country, questionnaires, and observation.

Keywords: Prizren, Kosovo, multilingualism, minority languages, language rights, language policy

\section{Introduction}

Language is one of the key elements for the establishment and maintenance of interpersonal relations, transfer of attitudes, values, ideologies and cultural models of a particular community. Therefore, language cannot be seen independent from its speakers. It is simultaneously a reflection of their perception of the world and a means of forming value systems that assist us in the world and the people around us. When studying multilingualism, you come across different terminologies including Multilingualism, Bilingualism, Plurilingualism. To some extend they all refer to being competent in more than one language. There is no agreement of the number of languages nor the competence of nonnative languages. While Bilingualism refers to 
an individual speaking more than one language, multilingualism is seen as the phenomenon or situation involving several languages in communication. On the other hand, Plurilingualism for the Council of Europe refers to the repertoire of languages or linguistic varieties an individual may use. Analyzed from the morphemic point of view, multilingualism consists of "multi", which means a combination of many, and "lingualism", which is related to language. In the advanced Oxford dictionary, the term multilingualism is defined as "Speaking or using several different languages". Multilingualism is a topic that started to be analyzed more rigorously in the second part of the twentieth century and has become common in academic discourse. It belongs to the sociolinguistic field of language use studies in society. Multilingualism is a field of language studies further reconceptualized by translanguaging. Translanguaging is considered to be a post-multilingualism era, which defines multilingualism as a very simplistic way of language mirroring. According to L. Wei (2018). Today, hardly any country is monolingual. The reason for this phenomenon is simple: the need to communicate. Edwards (1994) points out that

A monolingual perspective is often, unfortunately, a consequence of possession of a powerful 'language of wider communication', such as English, French, German, Spanish, and other such languages. This linguistic myopia is sometimes accompanied by a narrow cultural awareness and is reinforced by state policies which, in the main, elevate only one language to official status. (Edwards, 1994).

A better idea of how multilingualism is spread will be achieved if the number of languages that exist in the world is compared with the number of official languages recognized by states. Based on information from the Ethnologue, $20^{\text {th }}$ edition, there are around 5000 distinct languages across 200 countries, but only a quarter of these countries have more than one official language, meaning that most languages fall under the category of minority or unofficial languages. Even stubborn regimes which have tried to impose a single language in their states have been unsuccessful in their mission. The Republic of Kosovo declared its independence as a multicultural and multilingual country. After a long struggle with language issues, In summary, multilingualism is a complex phenomenon that can be studied from different perspectives, including social and individual, sociolinguistic, educational, language policy, and psycholinguistics. As such, there are several definitions of multilingualism, depending on the branch of study examined by any particular researcher.

According to Franceschini (2009) "multilingualism is to be understood as the capacity of societies, institutions, groups and individuals to engage on a regular basis in space and time with more than one language in everyday life". (Franceschini, 2009, p. 33). 
Barker (2016) believes that "the focus on an individual language user and not just on statistically verified models of numerous language users should become the major aim of multilingualism research" (Gabryś \& Barker, 2016). Similar studies have been carried by sociologists and researchers from the social field of studies. Bloomfield (1933) defines it as "native-like control of two languages" (Bloomfield 1933, p. 56). Seen from the linguistic point of view, Diabold (1961) defines multilingualism as "a positive phenomenon because it has a direct impact on the development of language skills, and bilingual or multilingual people are naturally considered more competent". Diebold (1961) points out that "bilingualism commences when a person begins to understand utterances in a second language, but is unable to produce utterances". (Diebold, 1961). One of the simpler definitions of multilingualism is by Kachru (1986) who defines the phenomenon as "the linguistic behavior of members of a speech community which alternatively uses two or more languages depending on the situation and function" (Kachru, 1986. P. 156).

The European Union as a multilingual organization has published many documents on the issue of multilingualism. In 2007 it defined the phenomenon as follows: "The ability of societies, institutions, groups, and individuals to engage on regular basis with more than one language in their day to day lives." (EU Commission, 2008). From a social point of view Cenoz and Gorter describe multilingualism as (Cenoz \& Gorter, 2006). From the applied linguistic view point, Wei (2008) defines multilingualism "as the ability to communicate in more than one language, be it active or passive (Wei, 2008). For the purpose of this study multilingualism is defined as the ability of using more than one language as an individual.

There are numerous reasons for multilingual situations in different countries and places. First, countries with multiethnic and multilingual population are often a result of migration, especially in recent years due to political crises around the world. People are always in motion seeking a better life and running away from wars. In addition, according to Edwards (1994) "There are also other reasons including, globalization and trade. Immigrants to a new country bring their languages into contact with other immigrant languages, and with those of existing populations." (Edwards, 1994, p.33). Ultimately, it is the government, the political will of the country that will institutionalize the language and offer basic human rights to people using different languages issues of political allegiance, national identity and power must also be borne in mind. According to Weinreich (1945), "A language is a dialect that has an army and navy" (Weinreich, 1945). He adds that "one of the basic reasons for multilingualism is simply the need to communicate". Finally, everyone should be free and enjoy the freedom of language use. If the rights to communicate in a certain 
language are officially banned by government, it is the people who will find a way to communicate. According to Edwards (1994):

"People will always find a way to use their language within their communities, regardless of the approach that governments or states might have. Whether or not a language is in some way or other recognized in legislation, many societies try to assess regularly the type and extent of multilingualism within their borders." (Edwards, 1994).

\section{Methodology}

Questionnaires, observation and document analysis are the main methods used in this research. The questionnaire was designed carefully in order to get as much information as possible about the language situation in Prizren, but at the same time not to overload it with questions so that it became challenging for the respondents to complete. A total of fourteen questions were included in the survey in order to achieve the research goal. Questionnaires are one of the main methods of research used to acquire necessary data for the analyses of the language situation in the city of Prizren. It is important to point out that the questionnaires were anonymous which guaranteed confidentiality of the respondents and in this way a truthful data was guaranteed. The first couple of questions were regarding the gender and whether the respondents were married or not. All other questions were directly related to language use and personal opinions on the issues of language. A total of 221 questionnaires were completed and used as the basis for the interpretation of the data. Because language can be a complex or sensitive issue, especially in the time and place of this study, questionnaire respondents needed to be old enough in order to understand some concepts of language and the socio-political situation of the city and the country. This is the reason the survey was conducted at the University of Prizren, specifically at the Faculty of Education where studies are offered in three community languages, Albanian, Bosnian and Turkish. Observation was also used to measure the use of languages in real life situations and in public places such as streets, gathering points, and institutions like schools and public administration buildings. Observation was conducted under a few basic principles: observation of conversations was conducted without the knowledge of the actors involved and without interviews prior to or following the observation, and spoken language was the focus of observationthe length of conversations was not deemed relevant. Finally, document analysis of language policy was used to triangulate the findings out of questionnaires and observation. 


\section{Analysis and Interpretation of data}

\section{Language use in formal communication}

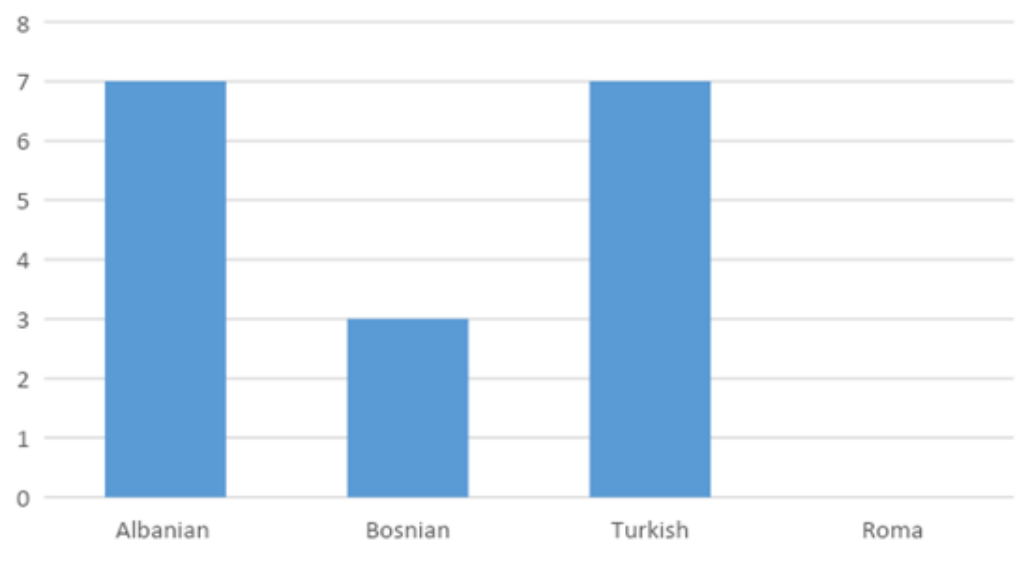

Albanian and Turkish were used more than other languages in formal communication. An equal number of conversations in these two languages could be registered in the municipality and the court of Prizren. Around fifteen percent of conversations were recorded in Bosnian, which reflects the Bosnian community living in Prizren.Questionnaires

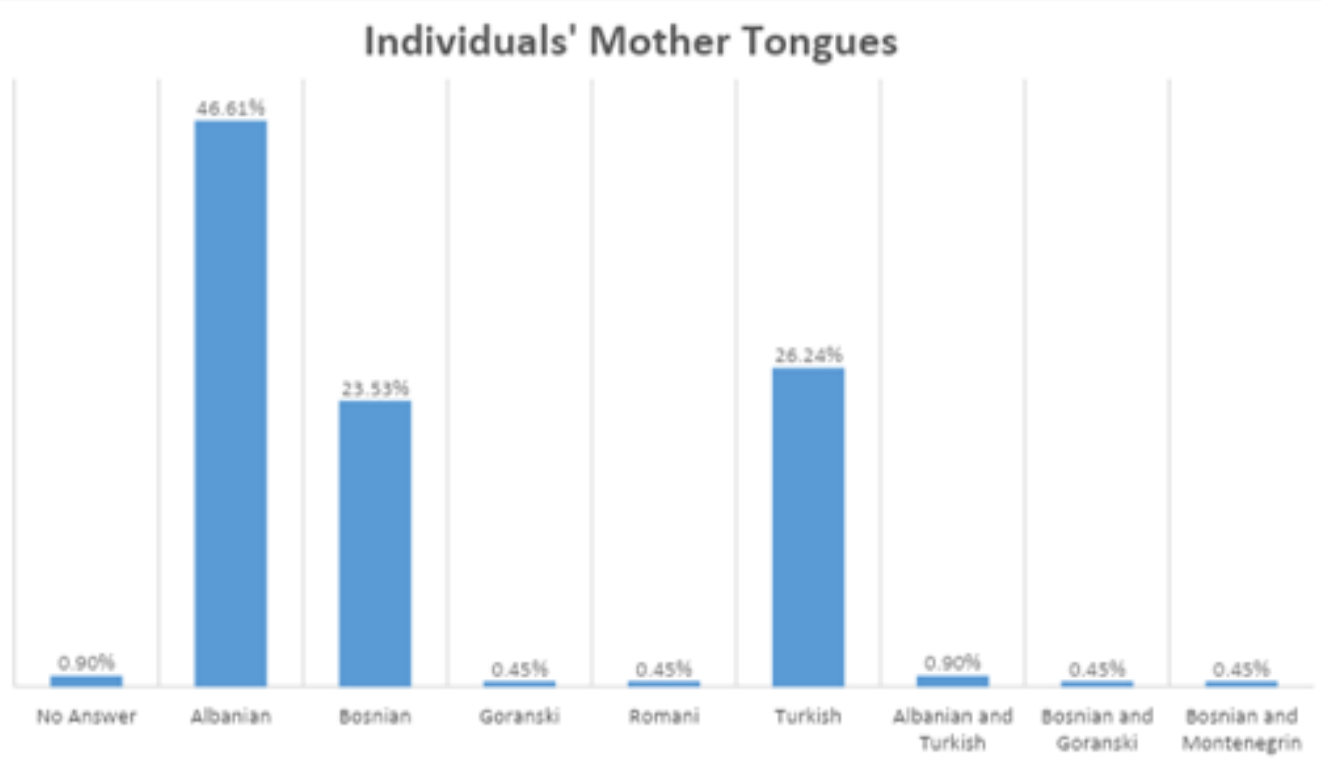


Out of 221 respondents, 219 responded to the question "What is your mother tongue?" Based on the responses, five different local languages could be identified as mother tongues of our respondents. 103 declared that their mother tongue is Albanian, 52 Bosnian, 58 Turkish, 1 Gorani, and 1 Romani. Two respondents declared that they are fully bilingual and that their mother tongue is Albanian and Turkish, and one fully bilingual respondent declared that his mother tongues are Bosnian and Gorani.

\section{Knowledge of other local languages}

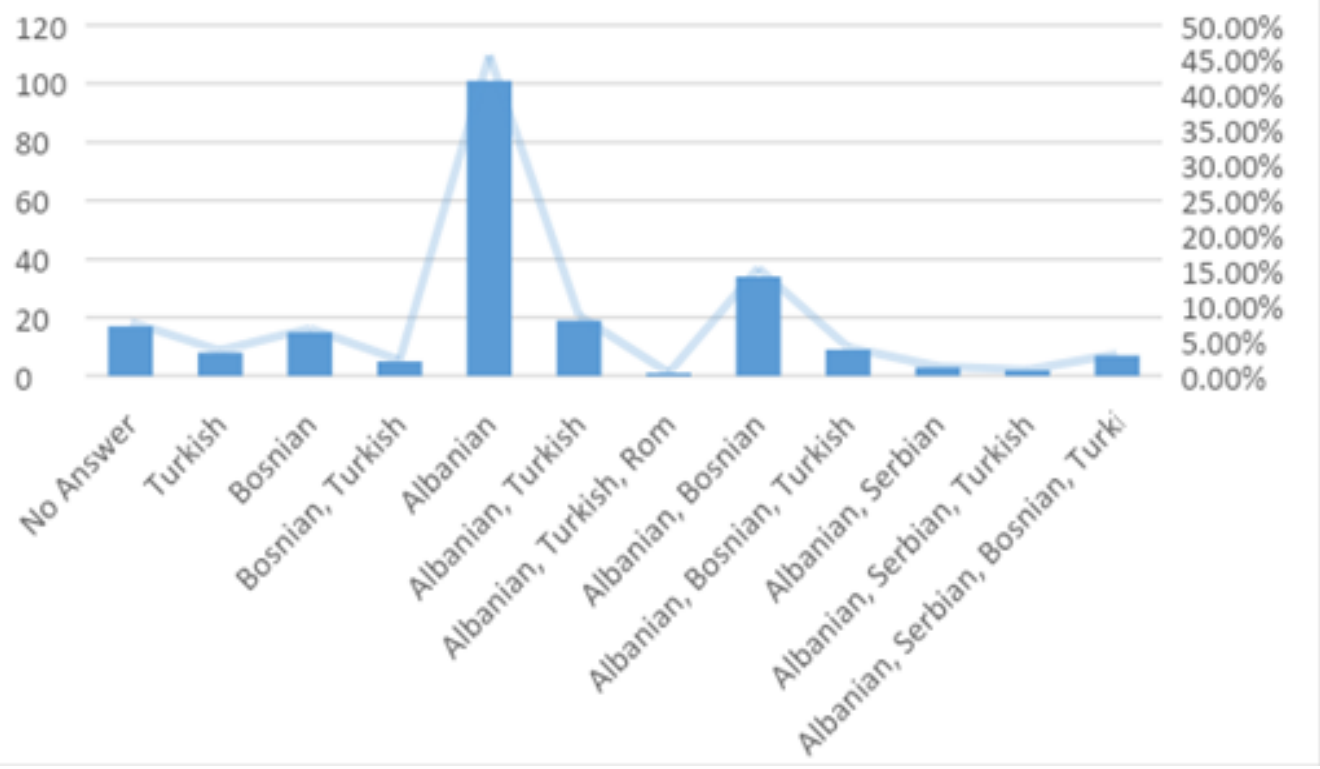

On the question "What other languages do you speak besides your mother tongue?" approximately $8 \%$ of the respondents did not specify if they speak another local language. $3.62 \%$ declared that they can only Turkish, $6.79 \%$ declared that they can speak only Bosnian, and $2.26 \%$ are multilingual in Bosnian and Turkish. The majority of respondents, 45.7\%, declared that they can speak only Albanian. 5\% of respondents were bilingual in Albanian and Bosnian. Trilingual respondents, speaking Albanian, Bosnian, and Turkish, represented approximately $7 \%$ of the respondents. There is only one student who declared that he could speak Roma. 


\section{Ways of learning other local language}

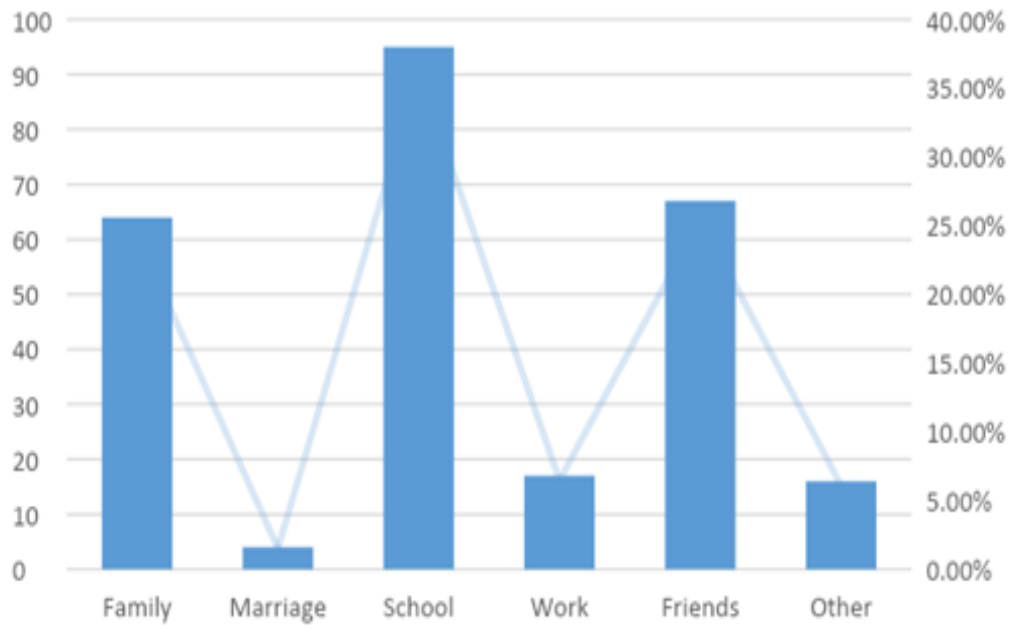

Around $35 \%$ of the respondents declared that they learned the language at school. $25 \%$ declared that they learned the second local language from friends and in their families. $5 \%$ of them said that they learned the language at work, marriage or some other place.

It is important to point out that based on study plan and program in elementary schools, children attending school in the Bosnian or Turkish language tracks are obliged to study Albanian in school, whereas Turkish and Bosnian are not offered to children attending school in the Albanian language track.

The majority of employees in public institutions are Albanians and the language of communication is Albanian. Employees coming from communities, being exposed to Albanian speaking majority are able to learn Albanian. Albanians are exposed to Bosnian and Turkish in neighborhoods with a high density of these communities, and as a sign of respect they often speak the language of these communities. Turkish language is considered traditional, spoken during different periods of time regardless of the official languages spoken in public institutions. As the survey showed, it is important to point out mixed marriages which are happening among these communities in all possible combinations. Mixed marriages in terms of language may occur because people might pay more attention to the religious origin of their partners (although there are also cases of intermarriage between different religions). 


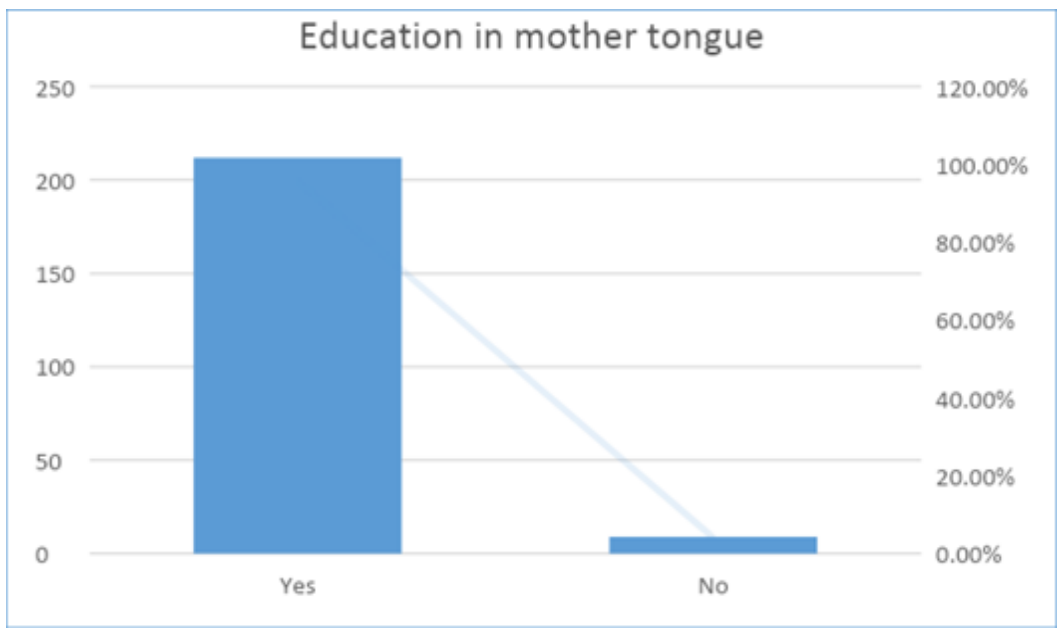

Education in one's mother tongue is guaranteed in the Constitution, the Law on Education, as well as in regulations applicable to all citizens of the Republic of Kosovo regardless of their nationality. This issue is explained in detail in the part on language legislation and situation in the Republic of Kosovo. However many students, mostly children coming from the Bosnian and Turkish communities, decide to conduct their education in another language for different reasons. Based on the answers provided by the respondents, it comes out that around 5\% have decided to attend school in a language other than their mother tongue. The reasons might be different, but most commonly the reason is easier integration in society, plans for further studies in fields that are not offered in community languages, and better job opportunities. These results are specific to the respondents, who belong to the post war generation; if generations educated before the war in 1999 were included in the questionnaire, this result would be different.

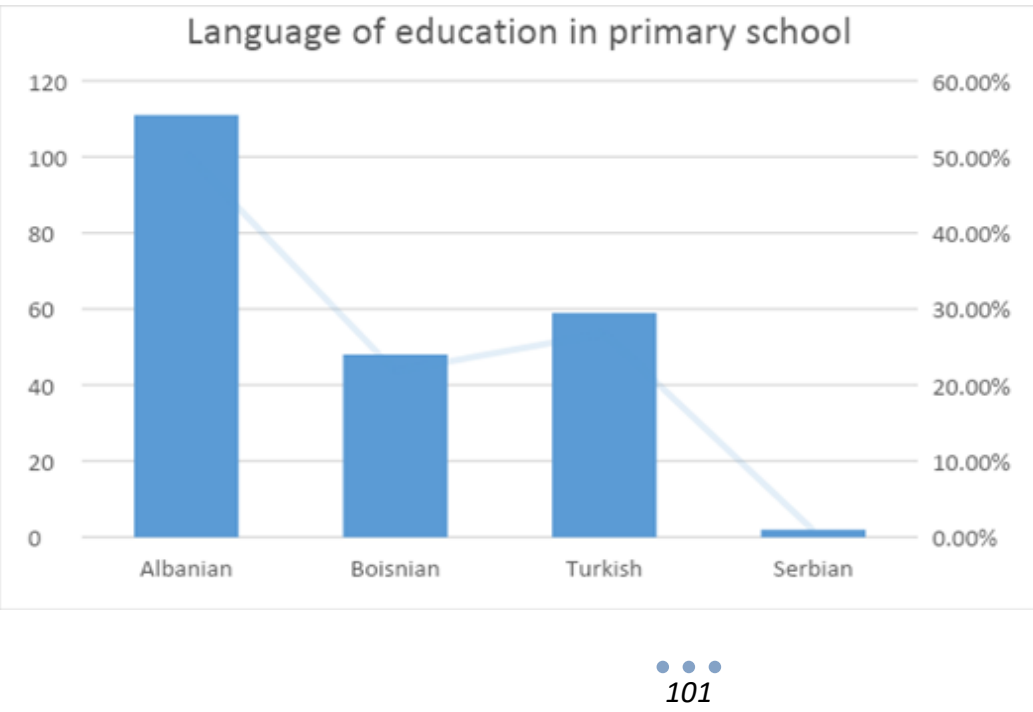


On the question, "In what language did you get educated?", around $60 \%$ of the respondents declared that they attended Albanian-language schools, 22\% declared that they attended Bosnian-language school, and 25\% of said that they attended Turkish-language schools. Less than 3\% declared that they attended school in Serbian or other languages. The above results are to be expected and are in line with the population in Prizren and the region. It is important to point out that there are no official schools operating in Serbian under Kosovo institutions, even though there is legal basis for this. People have changed their language of interest to follow education, especially primary and secondary education. Before 1999, Serbian was the only official language at all levels, even though the languages spoken by population on the ground were in total discrepancy with this. During that time, communities, mainly Turks and Bosnians, chose to attend Serbian-language schools, mainly because it was the easiest way of getting a job and a closer relationship with the regime, which could bring concrete privileges in a time of economic scarcity. The situation drastically changed after 1999 and after the language of administration was replaced with Albanian. After the installation of the United Nations administration, known in that time as UNMIK, all languages that existed in Kosovo depending on the region and the settlements of communities were in use. Since that time, minorities are increasingly adapting to Albanian and attending Albanian-language schools, considering it as the language of the future in the country which will ensure better prospects, easier integration and an easier path to employment. 


\section{Freedom of using mother tongue}

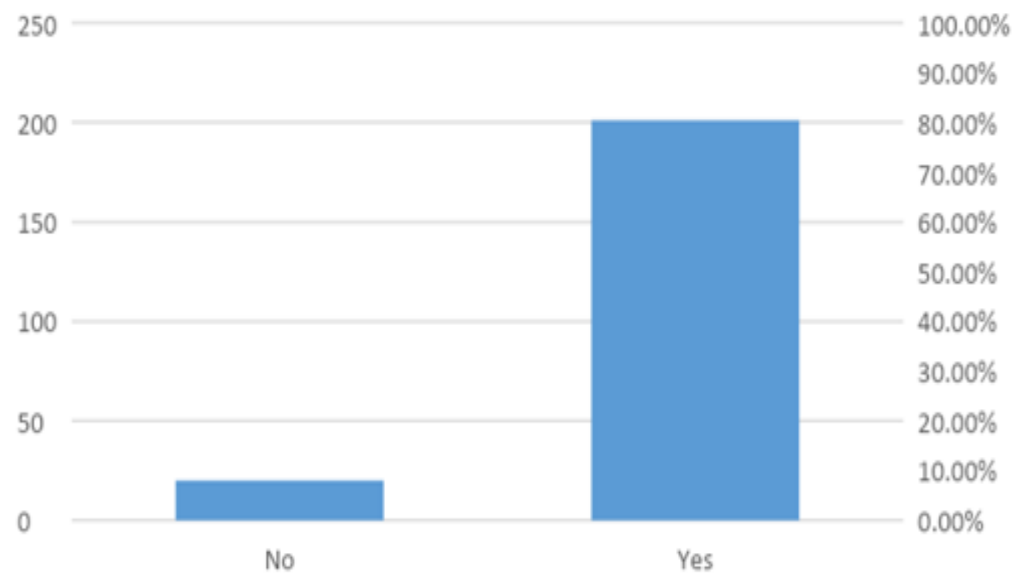

In response to the question, "Do you feel free in using your mother tongue?", $90 \%$ of respondents answered that they feel free using their mother tongue and around $10 \%$ answered that they do not feel free using their mother tongue. The $10 \%$ of the respondents belong to the minorities-mainly Bosnians, whose language is very similar to Serbian. This is due to the prejudice that the majority of Albanians might have towards them because of the language use and the well-known relationships between the communities. The situation has changed in positive way since 1999 when the armed conflict ended. Tensions reduced, the Albanian majority is used to having communities around speaking other languages and can distinguish the Muslim community speaking Slavic language with the Serbian community. 


\section{Language use in state institutions}

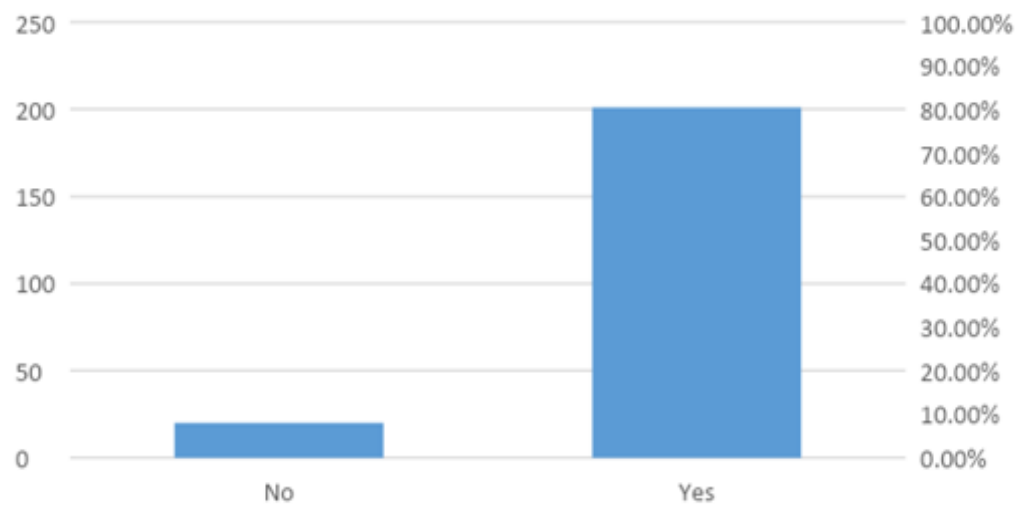

The above graph compares attitudes towards using local languages in state institutions. As seen in the graph, Albanians dominates, with around $50 \%$ of respondents who only use this language in communication in the public institutions. Linear representation of Bosnian and Turkish is to be noticed. The majority of respondents coming from minority language groups also use other local languages in accomplishing public services in local and central institutions.

Challenges completing obligation in the state administration

\section{Difficulty Completing State Obligations}

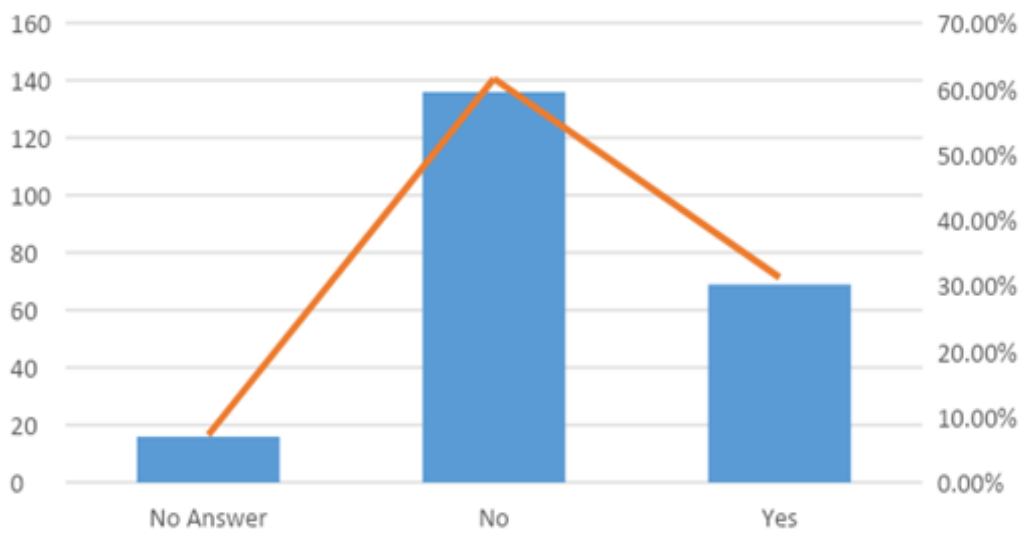


On questions "Do you face difficulties in accomplishing everyday tasks due to lack of language knowledge?", "What language do you use in accomplishing official tasks (school, municipality, state institutions)?", "Can you complete different tasks in state institutions in your mother tongue?", and "Have you ever met state officials that can't speak your mother tongue?", responses show that around 35\% of respondents face difficulties in conducting official tasks at state institutions due to the lack of knowledge of local languages by the state employees in local administration. Forty percent of the respondents have met state officials that can not speak the language of the respondent. Around $15 \%$ of the respondents didn't answer. This shows a huge gap between the legislation on language use and the real situation on the ground, even though there are guaranteed services to be offered in community languages, especially in the areas populated by minorities where there is special legislation of language use in place as explained it the part on language legislation in Kosovo. This situation is created mainly because the older generation of local administrators who were part of the ex-Yugoslav system spoke local minority languages, and after their retirement they were replaced mainly by young Albanians who could speak only Albanian and, as shown in the graph on language learning preference, do not show an interest in learning other local languages. This has brought about a situation in which many officials working in the administration can only offer services in Albanian. Services in other local languages can be mainly offered by employees coming from minorities who, tend to already be bilingual or multilingual and, based on the statistics shown on language learning preference, show more interest in learning other languages.

\section{Analysis of the Constitution, laws and official languages in the Republic of Kosovo}

The language situation in Kosovo is institutionally well protected by laws and regulations on official languages. The Constitution is the highest legal act of the Republic of Kosovo, laws and other legal acts should be in full compliance with it. Article 1 of this document states, "The official languages in the Republic of Kosovo are Albanian and Serbian, Turkish, Bosnian and Roma and have the status of official languages at the municipal level or will be used as official at all levels, in accordance with the law."

In central institutions, official languages in Kosovo enjoy an equal status. All laws adopted by the Assembly of Kosovo must be issued and published in the official languages. Each version is equally important. All approved must also be published in Bosnian and Turkish. Official notes and documents must be published in official 
languages. If you are an employee or worker in any of the central institutions, you have the right to use any of the official languages in your work. This right must be made possible by the institution, during the debates that take place in it, procedures and meetings, as well as during any public meetings organized by that institution. Based on your request, the institution must enable translation at all meetings, from one official language to another. If your mother tongue is not one of the official languages in Kosovo, special provisions apply to you in the context of central institutions. If you are a member of the Government and your native language is not one of the official languages, you have the right to use your mother tongue at meetings of central institutions, as well as at any public meeting they organize. At your request, central institutions must provide translation. If you are a member of the Assembly and your mother tongue is not one of the official languages, you have the right to use your mother tongue in work, debates or other proceedings in the Assembly and its committees, as well as at any public meeting it organizes. At your request, you must be provided with translation into your mother tongue and from it. Any document you submit in your native language must be translated into official languages, and all replies must be delivered to you in your native language. If your mother tongue is not one of the official languages in Kosovo and if you want to file a complaint with the Ombudsman, you have the right to present your oral or written submissions to the Ombudsman in your native language

As stated above, the Albanian and Serbian languages enjoy equal status throughout Kosovo and at all levels of government. However, languages of other communities may be elevated to the status of official languages at the municipal level, provided certain demographic conditions are met.

In municipal institutions, official languages in the municipality enjoy equal status. The term 'official languages' here refers to Albanian, Serbian and the language of any other community that has official status at the municipal level. This includes the right to receive available services and public documents in that language. Each municipal representative and executive body is obliged to enable this. All official languages in the municipality have equal status in the meetings and activities of municipal institutions. Based on request, municipal institutions are obliged to enable translation from one official language to another during meetings in the municipality, as well as during public meetings organized by the municipality. Provisions and by-laws must be printed and published in the official languages of the municipality. All versions have the same weight. Official documents must be kept and published in all the official languages of the municipality. This includes notes from meetings, official notes from municipal, representative and executive bodies, public registers, etc. The official 
names of municipal institutions and bodies must be printed in the official languages of the municipality, as well as official labels with names of municipalities, villages, roads, streets and other public places.

The OSCE regularly publishes reports on the overall situation in Kosovo, including information about language rights and use. Their reports find that actual language rights and use are not consistent with the articles from the Constitution of the Republic of Kosovo and other legislation, mainly due to technical and financial issues. here is the conclusion of their report on language use in Kosovo:

In conclusion the implementation of the Law on the Use of Languages remains unsatisfactory regarding the translation of draft legislation. Poor translation of legislation is prevalent both at the central and local level. According to the assessment, many of the identified obstacles to timely and accurate translation of draft legal acts are common amongst most Kosovo institutions, including the following: lack of professional qualification of translators and insufficient funding of translation units; lack of systematic proofreading; lack of public awareness and information; and insufficient supervision. Interview results also suggest that a lack of will on the part of the responsible institutions to draft and issue legislation in all official languages plays a role in a number of cases. (OSCE report on Multilingual Legislation in Kosovo and its Challenges, page 31)

\section{Observation}

Observational data was collected via the observation form (see section 3.3), and results were interpreted keeping clear methodological principles in mind. Choosing the right route for the observation was important in order to accurately reflect what is happening on the streets of the city. It also represents people coming from all communities. This was especially important to avoid places frequented by only a particular community and made the data logical and a higher number of conversations could be documented. The observation was done along the predesigned route, which is frequented by all groups of the population and during the peak time when there was the change of the shift in the schools and the midday break for officials. This made the scenery diverse and adequate for observation. 


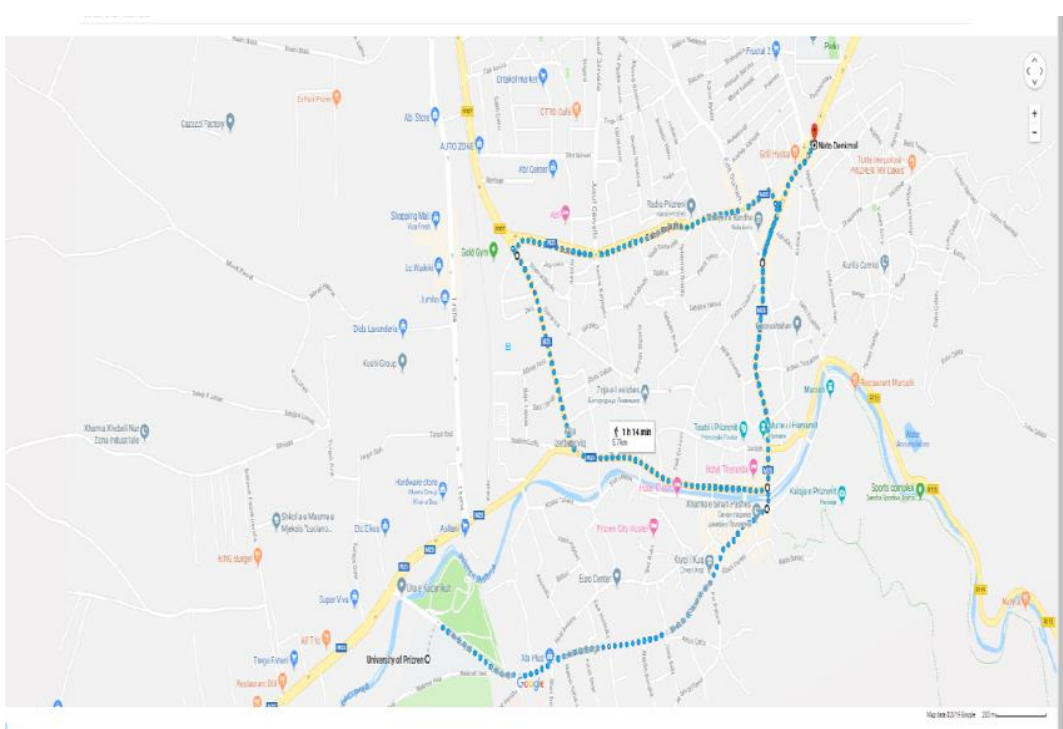

Figure 9 Observation route

\section{Age of observed participants}

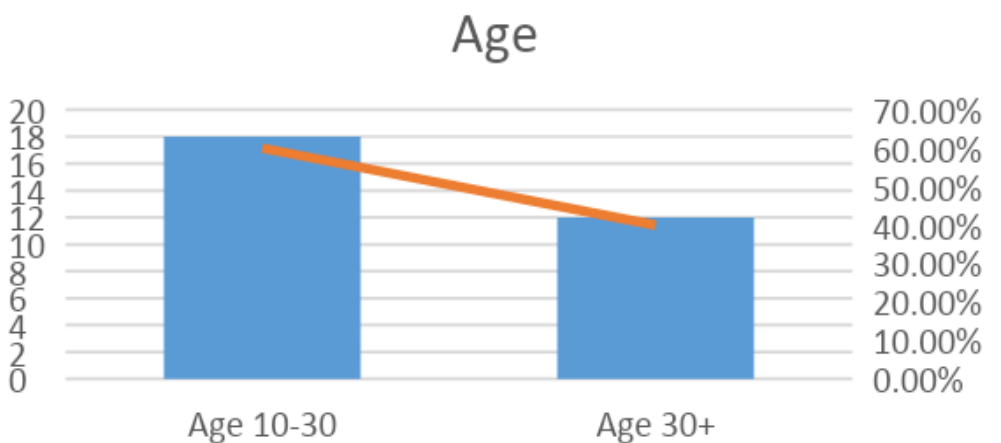

Based on our assumption, people aged 10 to 30 years old were around $60 \%$ of the participants and $40 \%$ were above 30 years old. 


\section{Language use in daily communication}

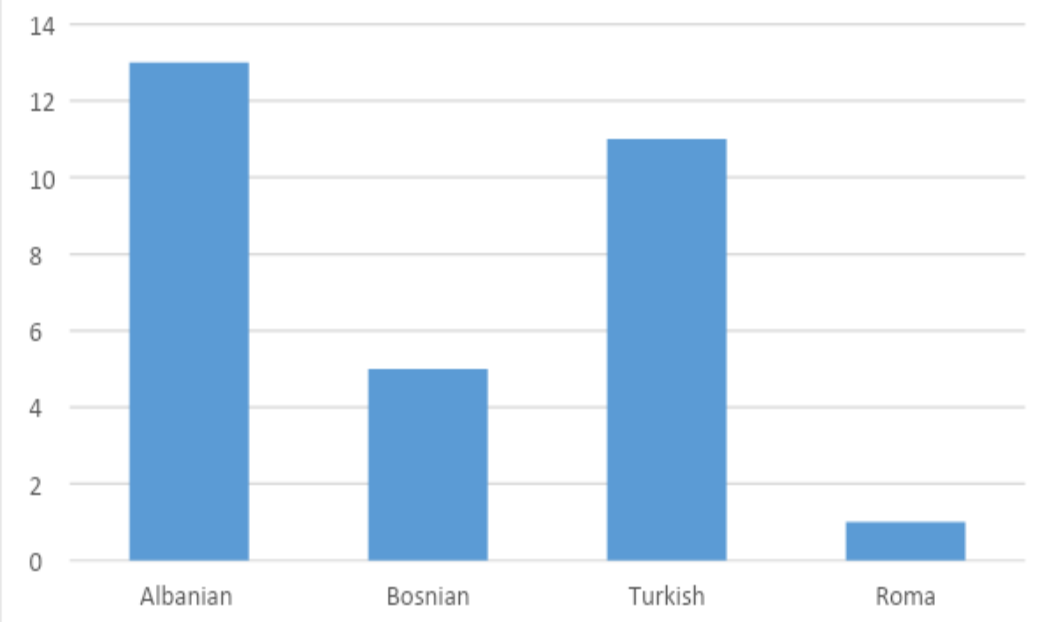

As expected, the majority of the conversations recorded were in Albanian (approximately $50 \%$ of the conversations). Forty percent of conversations were conducted in Turkish, which was a not expected, considering the percentage of Turkish inhabitants in Prizren. Ten percent of the conversations observed were in Bosnian and only one conversation was observed in the Romani language.

\section{Conclusion}

The city of Prizren and its surroundings can serve as an example of mutual language interferences and the emergence of bilingualism and multilingualism, but also the preservation and affirmation of multilingualism. The questionnaires and observation present clear evidence and reasons for multilingualism in Prizren including mixed marriages, education, integration, employability.

The survey clearly showed that the new generation that has gone through the education system in the aftermath of these changes exhibit lower levels of multilingualism, and value the multilingual tradition less than previous generations. The multilingual tradition, however, based on the responses by language minority students, remains strong.

The survey inquires about language background, capacity, values, and experiences. The University has three language tracks, Albanian, Bosnian, and Turkish, and surveys in each respective language were handed out to students in these courses. 221 
surveys in total were returned, approximately half from the Albanian classes, and a quarter each from the Bosnian and Turkish language classes.

The survey results confirm anecdotal observations about the multilingual trajectory of Prizren. Albanian, Bosnian, Turkish, and Romani are used to describe the languages spoken in the Prizren area, which also reflects the main groups

The role of Turkish in the city is what makes the city so unique. Prizren continues to maintain an urban Turkish-speaking culture that is distinct from ethnicity. Speaking Turkish is not necessarily a sign of Turkish identity, but rather one of urban cultured identity. This was true of most Islamic urban spaces in the Ottoman Balkans, and only survives as a living tradition today in Prizren and a few places in North Macedonia. Turkish continues to be a language of sophistication and prestige in Prizren, though not in the rest of Kosovo. According to interviewees, Turkish-speakers are often regarded as snobby and haughty, though people who don't speak Turkish will still make efforts to associate themselves with the Turkish-speaking culture as a way to establish their belonging in the city. In the survey results, the only people who claimed mother tongues different from the language of the survey they were filling out (meaning they had mother tongues different from the language track of their college education) were on the Turkish language survey. Not only that, but these 8-9 people all grew up in Prizren, indicating that Turkish still has a high social value in the city. In the flexible ethnic space of Prizren, simply speaking Turkish can establish your rights as an ethnic Turk, which can open up affirmative action jobs in the public sector or even open the door to migration to Turkey, a popular route given Kosovo's dire economic situation.

One survey question asked, "How important is it to know the local languages in Prizren?" with 1 being "not important" and 5 being "very important". The answers from Albanians, Bosnians, and Turks resulted in predictable fashion. Albanians on average see much less importance in learning local languages, while the majority of Bosnians and Turks deemed this as "very important". The single Romani survey respondent rated the importance of learning local languages as a 5, "very important", and said he speaks Romani, Albanian, and Turkish. A clear trend emerges that the more vulnerable communities see the necessity for multilingualism to function in Prizren, while Albanians know they mostly can get by with local language monolingualism. Although the average valuing of local language multilingualism by Albanians was significantly lower than the other communities, there are still a significant number of Albanians who rated it as a 4 or 5 . We wondered whether there would be a significant difference in how Albanians from Prizren and Albanians from 
elsewhere valued local language multilingualism, expecting that "Prizrenali" would support multilingual urban traditions.

The survey showed that Albanians from Prizren rate the importance of knowing local languages higher than those from the village or other parts of Kosovo do, as expected. In plain numbers, almost as many Albanians from Prizren rated the importance of knowing the local languages at the highest level as did Albanians from outside Prizren, even though Albanians from Prizren represented less than a quarter of the Albanian respondents. Albanians from Prizren on average rated local language importance at 3.4 while Albanians from elsewhere on average rated 2.66. This difference was not as large as might have been expected based on what people have asserted as the differences between urban and village cultures.

These data supports previous observations and predictions as to the relative importance each community would place on local language multilingualism. But what of actual multilingualism? Albanians were shown to be overwhelmingly local language monolingual, while Turks and Bosnians had a high degree of local language multilingual capabilities. The differences were starker than expected. Most of the respondents on this survey were 18-21 years old. In our survey more Turks have local language trilingualism than Albanians having just bilingualism, and there were twice as many Albanian survey respondents as Turks. Almost no Turks are monolingual, whereas almost $80 \%$ of Albanians are.

There are interesting differences in multilingualism between the Turks and the Bosnians. More than $25 \%$ of Bosnians are monolingual, while almost no Turks are. This is likely because most Turkish speakers in Kosovo come from Prizren and grow up in a multilingual space. Finally, Turkish-speaking families have a reputation for valuing education, holding jobs in medicine, media, and law, and overall being part of the urban elite. Most Bosnians come from small linguistically homogenous mountain villages their tradition vocations are in small businesses in food and service, rural agricultural work, and manual labor.

Even though the majority of Albanians said they valued local language multilingualism, only about $20 \%$ of them are able to speak either Bosnian or Turkish, and only one reported being local language trilingual.

The responses on willingness to learn local languages have showed that the multilingual tradition of Prizren will be kept alive for a time longer by the linguistic minorities, out of the necessity to adapt to the now Albanian language environment, but without reciprocal learning, in a generation or two the vibrant Balkan Ottoman- 
style multilingual urban space may have shifted towards greater local language monolingualism.

The examination of the language legislation demonstrated that there is good legislative base for language use in Kosovo, especially for the use of community languages in all spheres of life. It is regulated by the Constitution, law and regulations for language use. The Office for language use and rights constantly monitors the situation of languages at all levels and annually reports and comes with concrete measures that have to be undertaken for improving the situation. Other national and international also monitor the situation and report about it.

Based on the responses to our questionnaire and observations, the following concrete conclusions can be made:

As expected, Prizren is a multilingual city where people in their daily communication use Albanian, Bosnian, Turkish and Roma. People use these languages freely in formal and informal situations, at home and in the institutions.

There are many reasons for the multilingual language situation in Prizren including tradition, mixed marriages, business, and education.

All ethnic communities have their right guaranteed to enroll in education in their own language at all levels, except the Romani community, mainly because of the lack of standardized Romani language and lack of professional capacities.

All communities appreciate the laws and regulation on language use and find them appropriate offering them legal base for representation and language use in any given situation. On the other hand, the state of Kosovo should work harder and provide more capacity for implementation of the legislation.

The freedom of language use mainly by the Bosnian community has been improving since 1999. According to S. Neziri and S. Idrizi, immediately after the war there were some cases reported of people being asked and warned not to talk Bosnian, mainly due to similarity to Serbian language. The questionnaire results indicate this may still be a concern among the Bosnian community today.

The majority of people who responded to the questionnaire regardless of their language and ethnic background are willing to learn other local languages.

There is a discrepancy between the language legislation which is quite affirmative and the language situation in the field. The majority of respondents indicated that they faced difficulties in accomplishing tasks in public institutions due to lack of language 
knowledge of the officials. The government of Kosovo should put more effort into respecting the language regulation by offering language training for employees.

There is a huge discrepancy between the languages spoken in Prizren and the linguistic landscape, where there is the predominance of the Albanian language. There could be two reasons for this: 1. Awareness that people are multilingual and can understand the Albanian language, and 2. Because of the similarity of Bosnian language with Serbian, owners don't want to identify themselves with Serbian because of the prejudice that people might have towards it. A further study on reasons of language use could give a better understanding of the issue.

We could not notice any prejudice between communities. People consider multilingualism in Prizren a natural phenomenon that has always been around. As such, it is considered normal and people unconsciously are part of it.

\section{References}

[1] Barker, D. G., Gałajda, D., Wojtaszek, A., \& Zakrajewski, P. (2017).

[2] Bugarski., R. (2007). Lingvistika u primeni. Beograd: Čigoja štampa.

[3] Commision, E. (2008). EU-Multilingualism-Policy_2008. Retrieved from http://ecspm.org/wp-content/uploads/2016/04/EU-MultilingualismPolicy 2008.pdf

[4] Diebold, R. (1961). Incipient bilingualism. In: Language

[5] Edwards, J. (2013). Bilingualism and. In E. b. Ritchie., The Handbook of Bilingualism and Multilingualism, Second Edition. (pp. 1-20). Blackwell Publishing Ltd.

[6] Edwards, J. (1994). Multilingualism, London: Routledge Publishing Company.

[7] Edwards, J. (1995). Multilingualism. London, New York et al.: Penguin Books.

[8] Edwards, J. (2007). "Societal Multilingualism. Reality, Recognition and Response.” In: Handbook of Multilingualism and Multilingual Communication. Ed. by Peter Auer, Li

[9] Franceschini, R. (2009). The genesis and development of research in multilingualism: Perspectivesfor future research. In L. Aronin \& B. Hufeisen (Eds.), The exploration of multilingualism (pp. 27-62). Amsterdam: John Benjamins.

[10] Franceschini, R. (2011). Multilingualism and. The Modern Language Journal, 344-355.

[11] Gabryś-Barker, D. (2016). Applied linguistic and multilingualism. In D. Singleton \& L. Aronin (Eds.), Twelve lectures in multilingualism (forthcoming) 
[12] Kachru, B. (1986). The Alchemy of English: the spread, functions and models of non-native Englishes. Oxford: Pergamon Press.

[13] Parliament of the Republic of Kosovo. (2008). Law No. 03/L-068 On Education In The Municipalities of the Republic of Kosovo. Retrieved from: https://masht.rks-gov.net/uploads/2015/06/09-2008-03-1068-en.pdf

[14] Parliament of the Republic of Kosovo. (2011). Law No.04/L -032 On PreUniversity Education In The Republic of Kosovo. Pristina, Kosovo. Retrieved from : https://gzk.rks-gov.net/ActDocumentDetail.aspx?ActID=2770

[15] Parliament of the Republic of Kosovo. (2012, March 29). Law No. 04/L-046 On Radio Television Of Kosovo . Pristina, Kosovo, Kosovo. Retrieved from: https://gzk.rks-gov.net/ActDocumentDetail.aspx?ActID=2812

[16] Wei, L., \& Melissa G. M. (2008). The Blackwell Guide to Research Methods in Bilingualism and Multilingualism. Victoria: Blackwell Publishing.

[17] Wei, L. (2018). Translanguaging as a Practical Theory. In Applied Linguistics (pp. 9-20). Oxford University Press. 